\title{
Cardiopulmonary bypass reduction of bronchial blood flow: A potential mechanism for lung injury in a neonatal pig model
}

\author{
Christian Schlensak, MD \\ Torsten Doenst, MD ${ }^{a}$ \\ Stefan Preußer, BS ${ }^{a}$ \\ Mark Wunderlich, BS \\ Manuela Kleinschmidt, $\mathrm{MD}^{\mathrm{b}}$ \\ Friedhelm Beyersdorf, MDa
}

From the Departments of Cardiovascular Surgery ${ }^{\mathrm{a}}$ and Pathology, ${ }^{\mathrm{b}}$ Albert-LudwigsUniversity, Freiburg, Germany.

C.S. was supported by the Zentrum für Klinische Forschung of the University of Freiburg. T.D. was supported by the Emmy Noether-Program of the German Research Foundation (Deutsche Forschungsgemeinschaft, DFG, Do602/2-1).

Received for publication Aug 16, 2001; revisions requested Oct 24, 2001; revisions received Nov 14, 2001; accepted for publication Nov 20, 2001.

Address for reprints: Christian Schlensak, MD, Department of Cardiovascular Surgery, University of Freiburg, Hugstetter Strasse 55, D-79106 Freiburg, Germany (Email: schlensa@ch11.ukl.uni-freiburg.de).

J Thorac Cardiovasc Surg 2002;123: 1199-205

Copyright () 2002 by The American Association for Thoracic Surgery

0022-5223/2002 \$35.00+0 $\quad \mathbf{1 2 / 1 / 1 2 1 9 7 7}$

doi: $10.1067 / \mathrm{mtc} .2002 .121977$
Background: During total cardiopulmonary bypass, blood flow to the lungs is limited to flow through the bronchial arteries. We tested the hypothesis that bronchial blood flow during cardiopulmonary bypass is insufficient to prevent ischemia of the lung and that perfusion of the pulmonary arteries with oxygenated blood during bypass would reduce lung injury.

Methods: Eighteen piglets $(5.0 \pm 0.5 \mathrm{~kg})$ were subjected to 120 minutes of normothermic total cardiopulmonary bypass, followed by 60 minutes of postbypass perfusion. Nine of them received continuous pulmonary perfusion with oxygenated blood during bypass. Six additional piglets served as a control group and were mechanically ventilated after sternotomy for 180 minutes only. We quantitated bronchial arterial blood flow, tissue lactate content, and alveolar septal thickness and surface area. We also obtained bronchioalveolar lavage fluid samples.

Results: With the beginning of cardiopulmonary bypass, bronchial arterial blood flow decreased to $13 \%$ of baseline $(42.1 \pm 10.4$ to $5.6 \pm 1.0 \mathrm{~mL} / \mathrm{min})$. It remained decreased until the end of bypass and returned to starting levels 60 minutes after bypass. The decrease in bronchial blood flow was associated with a 3-fold increase in tissue lactate content. At the end of reperfusion there was a 2-fold increase in alveolar septal thickness and significant accumulations relative to control in the bronchoalveolar lavage fluid of albumin, lactate dehydrogenase, neutrophils, and elastase. Controlled pulmonary perfusion significantly ameliorated all the observed changes.

Conclusion: Cardiopulmonary bypass caused a reduction in bronchial arterial blood flow, which was associated with injury of the lung. Controlled pulmonary perfusion reduced injury to the lung during bypass. The inflammatory response, as evidenced by bronchoalveolar lavage fluid, may be caused by ischemia.

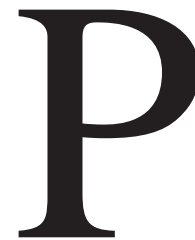
ulmonary dysfunction is a frequent complication during the postoperative course after cardiac surgery with cardiopulmonary bypass (CPB). Young age, preoperative pulmonary disease, and extended duration of $\mathrm{CPB}$ are all risk factors for such dysfunction. ${ }^{1} \mathrm{CPB}$ is also associated with a complex whole-body inflammatory reaction that may contribute to the development of multiple organ dysfunction, including postoperative lung injury. ${ }^{2-4}$ Recent investigations imply that pulmonary dysfunction may be related to an ischemic injury of the lung during CPB. ${ }^{5}$ Because blood flow to the lungs is limited to flow through the bronchial arteries during total $\mathrm{CPB}$, ischemic injury of the lung will occur if bronchial blood flow is insufficient 
to meet metabolic demands. When pulmonary blood flow ceases, bronchial arterial blood flow might be expected to increase as a compensatory measure. This expectation was observed experimentally when in 1847 Virchow $^{6}$ described an increased bronchial flow after ligation of the pulmonary artery (PA) in dogs. Thus far there are no reliable techniques available for the quantitation of bronchial arterial blood flow during CPB. It is unknown whether the bronchial arterial blood flow during total CPB is increased and whether it is sufficient to prevent ischemic lung injury. It is also unknown whether the reason for pulmonary dysfunction is related to ischemia of the lung, an inflammatory reaction, or both. The aim of this study was to quantitate bronchial arterial blood flow during CPB and to assess the effects of controlled perfusion of the PA during total CPB. Contrary to expectations, bronchial arterial blood flow was substantially decreased during $\mathrm{CPB}$, rendering the lung ischemic, and controlled pulmonary perfusion was able to reverse these changes.

\section{Methods}

\section{Animals and Protocols}

Male piglets $(n=24$, Deutsche Landrasse; Rein, Sulzfeld, Germany) with a mean weight of $5.0 \pm 0.5 \mathrm{~kg}$ (equivalent to 4 weeks of age) were used for the study. Use of the animals was approved by the animal welfare committee of the University of Freiburg. All animals received humane care in compliance with the "Guide for the Care and Use of Laboratory Animals" prepared by the Institute of Laboratory Animal Resources, National Research Council, and published by the National Academy Press, revised 1996.

The animals were divided into three experimental groups. Group 1 (conventional CPB, $\mathrm{n}=9$ ) was subjected to 120 minutes of normothermic total CPB without aortic crossclamping, followed by normal unsupported circulation for 60 minutes (reperfusion). Group $2(\mathrm{CPB}$ with PA perfusion, $\mathrm{n}=9$ ) was treated as group 1 but also received controlled perfusion of the PA. Controlled perfusion was performed with oxygenated, normothermic, autologous blood through a 6-mm polytetrafluoroethylene* tube, which was anastomosed to the main PA and connected to the CPB circuit beyond the membrane oxygenator. Lung perfusion was adjusted to a maximal pressure of $20 \mathrm{~mm} \mathrm{Hg}$, which was equivalent to a blood flow of 100 to $150 \mathrm{~mL} / \mathrm{min}$. During CPB, mechanical ventilation was interrupted. A positive end-expiratory pressure of 4 to $5 \mathrm{~mm}$ $\mathrm{Hg}$ was maintained for the duration of $\mathrm{CPB}$. No protamine was given at the end of CPB. Group 3 (control, $\mathrm{n}=6$ ) served as control and was ventilated after sternotomy for 180 minutes without establishment of CPB. CPB was established as described previously elsewhere. ${ }^{7}$

\section{Bronchial Arterial Blood Flow}

Bronchial blood flow was determined with fluorescent microspheres with four different color codes before $\mathrm{CPB}$, at the beginning and at the end of $\mathrm{CPB}$, and after 60 minutes of reperfusion. ${ }^{7}$ Microspheres $(15.1 \pm 0.2 \mu \mathrm{m}$ diameter $)$ were injected in a bolus $\left(2 \times 10^{6}\right.$ over 5 seconds) into the proximal aortic arch, distal to the arterial cannula. Ariz.

*Gore-Tex; registered trademark of W. L. Gore \& Associates, Inc, Flagstaff,
The reference samples were withdrawn from the descending aorta at the level of the diaphragm. The reliability of this approach was verified by ensuring identical results obtained by injecting microspheres into the left atrium or the aorta and collecting the references sample in the descending aorta. ${ }^{7}$ At the end of the experiments, the lungs were resected, the microspheres were filtered out of the digested lung tissue, and the light emission of the fluorescent dye was quantitated as described previously elsewhere. 7,8

\section{Lung Tissue lactate}

We determined lactate content of lung tissue as a marker for anaerobic metabolism before $\mathrm{CPB}$ and at the end of CPB. To assess the effects of the same period of total global ischemia on lactate production, parts of 6 samples (all before $\mathrm{CPB}$ ) were subjected to 120 minutes of in vitro ischemia by being placed in a vacuum-sealed plastic bag at $37^{\circ} \mathrm{C}$ in a water bath.

\section{Bronchioalveolar Lavage}

A bronchioalveolar lavage (BAL) was performed at the end of reperfusion, as described by Riedler and colleagues. ${ }^{9}$ Cell counts and solute components in the BAL fluid were analyzed.

\section{Histologic Examination}

At selected time points, samples were taken for histologic examination. At the end of the experiments, the lungs were explanted quickly and divided into 14 segments according to a standardized pattern. Tissue samples $(25 \times 25 \mathrm{~mm})$ were taken out of each segment and stored in a $4 \%$ formalin solution before the remaining lung tissue was digested to filter out the microspheres. At the time of specimen collection, the lungs were regularly ventilated. All histologic specimens were embedded in paraffin and serially sectioned. The sections were stained with hematoxylin and eosin, and alveolar septal thickness and alveolar surface area were quantified in each specimen by morphometric analysis (50 alveolar septa and 50 alveolar surface areas per biopsy specimen after randomization; Soft Imaging System $\mathrm{GmbH}$, Münster, Germany). Comparisons between the two time points were made between samples from the same side.

\section{Hemodynamic Data}

Standard hemodynamic monitoring was performed in all animals. Arterial blood pressure was monitored continuously in the abdominal aorta. Cardiac output was measured with a thermistor catheter (Pulsion-Cold-System; Pulsion \& Co Medical System KG, München, Germany) that was placed into the descending aorta.

\section{Statistical Analysis}

Statistical analysis was performed by repeated measures analysis of variance with post hoc analysis by Newman-Keuls test. Values are given as mean $\pm \mathrm{SD}$.

\section{Results}

\section{Hemodynamic Data}

Table 1 shows cardiac outputs and aortic pressures before and after CPB and pump flows and mean aortic pressures during CPB. Pump flow was adjusted to match cardiac output before CPB. Maintenance of this flow rate did not result in significant changes in mean aortic pressure. During 
reperfusion, both cardiac output and mean aortic pressure were slightly lower than before $\mathrm{CPB}$, although these changes were not statistically significant.

\section{Bronchial Blood Flow}

Figure 1 shows bronchial blood flows before $\mathrm{CPB}$, at the beginning and end of $\mathrm{CPB}$, and after 60 minutes of postbypass perfusion, either with or without controlled PA perfusion. There was a significant decrease in bronchial blood flow with the beginning of total CPB $(5.6 \pm 1.0 \mathrm{~mL} / \mathrm{min}$ vs $42.1 \pm 10.4 \mathrm{~mL} / \mathrm{min}$, or $0.7 \%$ vs $5.0 \%$ of cardiac output, $P<.01)$, which remained decreased until the end of CPB $(5.1 \pm 1.8 \mathrm{~mL} / \mathrm{min})$. Bronchial blood flow returned to nearly normal values during 60 minutes of postbypass perfusion $(25.6 \pm 10.8 \mathrm{~mL} / \mathrm{min})$. To examine the effects of pulmonary perfusion on bronchial blood flow during CPB, microsphere injections into the aorta were performed while controlled perfusion to the PA was applied. The decrease in bronchial blood flow during CPB was unaffected by pulmonary perfusion $(5.4 \pm 1.6 \mathrm{~mL} / \mathrm{min}, P<.01$ vs before $\mathrm{CPB})$ and also normalized during the reperfusion period $(34.7 \pm 13.5 \mathrm{~mL} / \mathrm{min})$.

\section{Lung Tissue Lactate}

Table 2 shows lactate contents of lung tissue before CPB and at the end of CPB with or without controlled PA perfusion. It also shows lactate content of lung tissue subjected to 120 minutes of total global ischemia in the water bath. During CPB, there was a 3 -fold increase in tissue lactate content. The same period of in vitro ischemia caused a 10-fold increase in tissue lactate content. Controlled PA perfusion attenuated the CPB-associated increase.

\section{Histologic Examination}

Figure 2 shows representative histologic specimens before CPB and after CPB with or without controlled PA perfusion. Figure 3, A, shows the average alveolar septal thickness from tissue samples of lungs before $\mathrm{CPB}$ and at the end of reperfusion after 120 minutes of CPB with or without controlled PA perfusion. Figure $3, B$, shows the average alveolar surface area of the same samples. At the end of reperfusion after $\mathrm{CPB}$ without $\mathrm{PA}$ perfusion, there was a 2 -fold increase in alveolar septal thickness and a 50\% decrease in alveolar surface area relative to prebypass values. Both the increase in alveolar septal thickness and the decrease in alveolar surface area were significantly reduced by controlled PA perfusion relative to values after CPB without PA perfusion. Alveolar septal thickness and alveolar surface area were identical in all corresponding lung areas.

\section{Bronchioalveolar Lavage}

Table 3 shows solute components and cell counts in BAL fluids obtained before $\mathrm{CPB}$ and at the end of reperfusion
TABLE 1. Cardiac output or pump flow during CPB and mean arterial perfusion pressure before $\mathrm{CPB}$, at the beginning and end of $C P B$, and at the end of 60 minutes of reperfusion

\begin{tabular}{lcc}
\hline & $\begin{array}{c}\text { CO/pump flow } \\
\left(\mathbf{m L} \cdot \mathbf{~ k g}^{-1} \cdot \mathbf{m i n}^{-1}\right)\end{array}$ & MAP $(\mathbf{m m ~ H g})$ \\
\hline Before CPB & $162 \pm 40$ & $58 \pm 5$ \\
Beginning of CPB & $178 \pm 42$ & $65 \pm 6$ \\
End of CPB & $184 \pm 34$ & $65 \pm 9$ \\
After 60 min of reperfusion & $134 \pm 34$ & $55 \pm 10$
\end{tabular}

Values are given mean $\pm S D, \mathrm{n}=18$ in each group. CO, Cardiac output; $M A P$, mean arterial pressure.

after 120 minutes of $\mathrm{CPB}$ with or without controlled PA perfusion. At the end of reperfusion after $\mathrm{CPB}$ without $\mathrm{PA}$ perfusion, there was a significant elevation of neutrophil counts, albumin content and lactate dehydrogenase activity in BAL fluid, which was not present in the group with controlled PA perfusion.

\section{Discussion}

During CPB in piglets, bronchial arterial blood flow was significantly reduced. This reduction in flow was independent of pulmonary perfusion and was present despite unaltered systemic arterial perfusion pressure. It was associated with metabolic and ultrastructural changes of lung tissue suggesting the presence of ischemia of the lungs during $\mathrm{CPB}$, which could be ameliorated by controlled perfusion of the PA. Furthermore, we demonstrated that indicators for an inflammatory response of the lungs obtained from BAL fluids could also be reversed by controlled perfusion of the lung. Because blood flow to the lung is limited to flow through the bronchial arteries during total CPB, bronchial arterial blood flow might be expected to increase as a compensatory measure to prevent ischemia of the lung. ${ }^{10}$ Bronchial arterial blood flow has been measured previously in animals with a variety of techniques. ${ }^{11-15}$ However, the results of these studies are inconclusive. Bronchial arterial blood flow was found to be increased ${ }^{10}$ or decreased ${ }^{16}$ after acute obstruction of the PA. During CPB, an estimate of bronchial blood flow is possible by collecting the blood returning to the vent catheter. ${ }^{11,12}$ Measurements of blood flow with this technique are likely to be inaccurate, however, because bronchial blood flow can accumulate in the lungs, and inadequate venting may occur during surgical intervention. ${ }^{11}$ Also, no information on bronchial blood can be obtained before or after CPB.

We assessed bronchial arterial blood flow with fluorescent microspheres before, during, and after CPB. In a previous study, we determined the accuracy of bronchial arterial blood flow measurement with this method. ${ }^{7}$ We found that the onset of $\mathrm{CPB}$ was associated with a persistent 


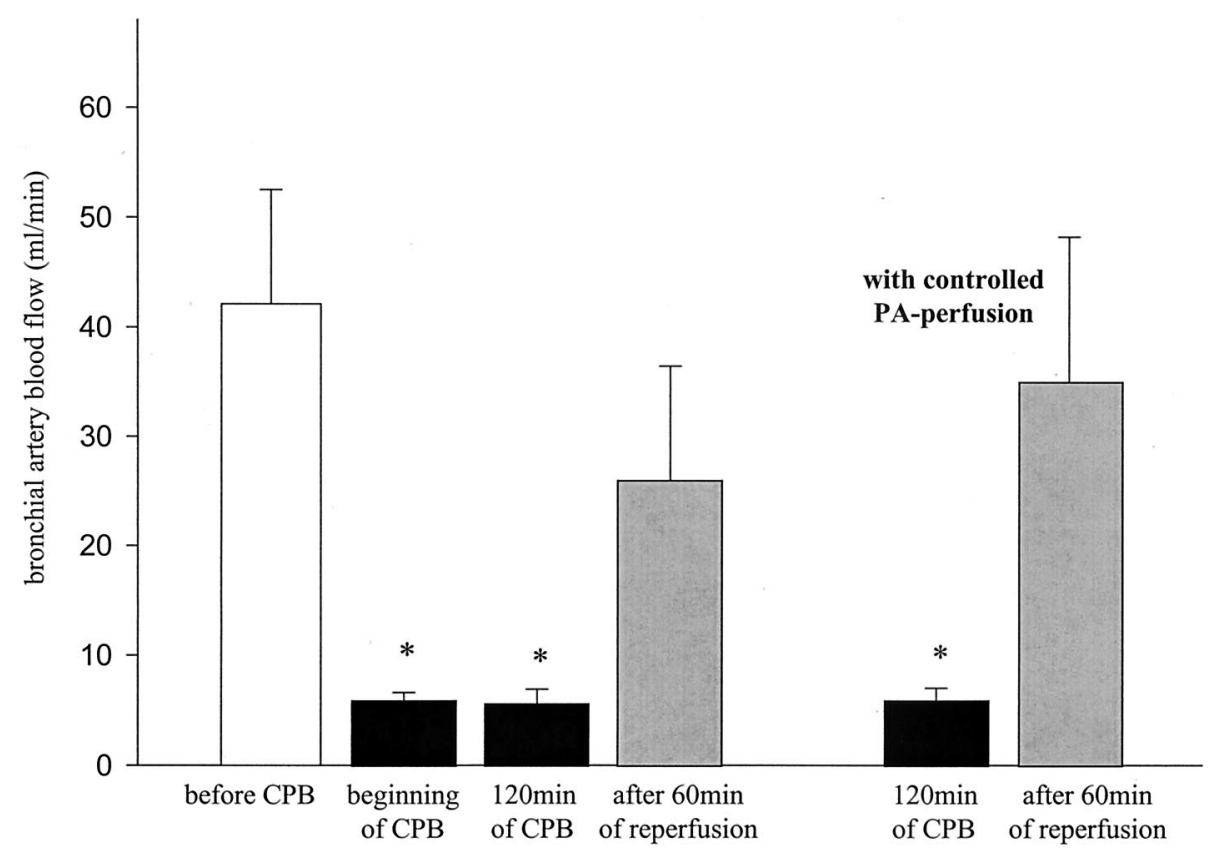

Figure 1. Bronchial arterial blood flows before CPB, at beginning and end of CPB with and without controlled PA perfusion, and after 60 minutes of reperfusion. Bar heights represent mean; error bars represent SD; $\mathbf{n}=9$ in each group. Asterisk indicates $\boldsymbol{P}<.01$ versus before CPB.

TABLE 2. Lactate content of lung tissue before CPB and after 120 minutes of CPB without and with controlled PA perfusion; additionally, separate tissue samples were exposed to 120 minutes of total, global ischemia (in vitro ischemia)

Tissue lactate

( $\mu \mathrm{mol} / \mathrm{g}$ dry weight)

\begin{tabular}{ll}
\hline Before CPB $(\mathrm{n}=6)$ & $13.6 \pm 6.2$ \\
120 min of CPB without PA & $36.5 \pm 10.9^{*}$ \\
$\quad$ perfusion $(\mathrm{n}=9)$ & \\
120 min of CPB with PA perfusion & $25.4 \pm 12.3$ \\
$(\mathrm{n}=9)$ & $133 \pm 33.9^{*} \dagger$ \\
120 min of in vitro ischemia $(\mathrm{n}=6)$ &
\end{tabular}

Values are given as mean $\pm \mathrm{SD}$. $P A$, Pulmonary artery.

${ }^{*} P<.05$ versus before CPB.

$\dagger P<.05$ versus after 120 minutes of CPB.

decrease in bronchial arterial blood flow. Bronchial blood flow normalized once physiologic perfusion conditions were reestablished by terminating $\mathrm{CPB}$. The reason for this decrease in bronchial blood flow is currently not clear. Bronchial blood flow is thought to be regulated by the inflation state of the lung as well as by the pulmonary perfusion pressure. The inflation state of the lung in our study was maintained by keeping a positive end-expiratory pressure of $5 \mathrm{~mm} \mathrm{Hg}$. Because there was no ventilation, it is conceivable that carbon dioxide accumulated during $\mathrm{CPB}$, causing bronchial arterial constriction. However, the sudden decrease in bronchial blood flow with the beginning of CPB and the constancy of this value until the end of CPB argue against this explanation. The absent pulmonary perfusion pressure during total CPB has to be considered as another potential explanation for our findings. For this reason, we assessed bronchial blood flow during CPB while controlled pulmonary perfusion was applied to maintain a physiologically usual pulmonary perfusion pressure. The decrease in bronchial blood flow was unaffected by pulmonary perfusion, eliminating this potential explanation. We therefore conclude that the decrease in bronchial blood flow appears to be a specific feature associated with CPB.

Because the perfusion pressure was unchanged with $\mathrm{CPB}$ in our experiments, it seems reasonable to speculate that the lack of pulsatile flow was responsible for the decreased bronchial flow. Decreased organ perfusion during nonpulsatile flow has been described for other organ systems (eg, kidneys, splanchnic region). ${ }^{17,18}$ If this speculation is accurate, the decrease in bronchial flow could be expected to be worse in actual patients, because the mean perfusion pressure is usually decreased with the beginning of CPB. One way to approach this problem would be the use of pulsatile CPB. Because of technical difficulties, the controversy of quantifying pulsatility, and the lack of superior clinical results, however, pulsatile perfusion has received only limited acceptance in clinical practice. Controlled pulmonary perfusion may provide an alternative approach. 

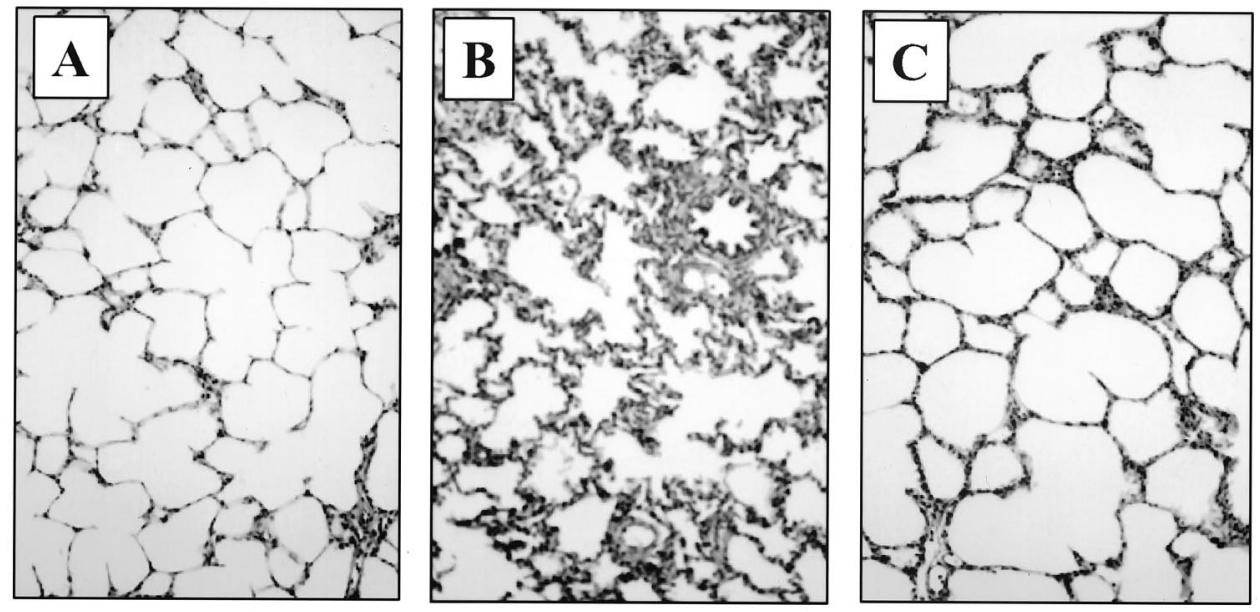

Figure 2. Representative light microscopic images of lung tissue (hematoxylin and eosin, original magnification $40 \times$ ) before CPB (A), after 120 minutes of CPB without PA perfusion (B), and after 120 minutes of CPB with controlled PA perfusion (C).

A

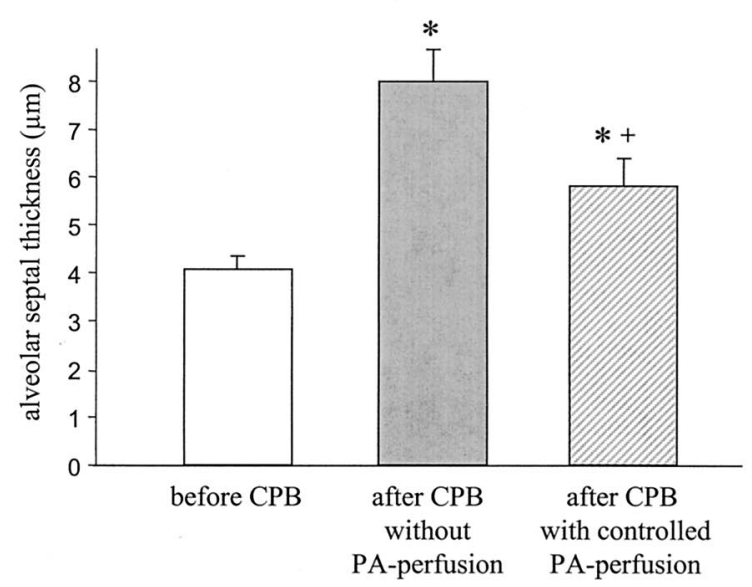

B

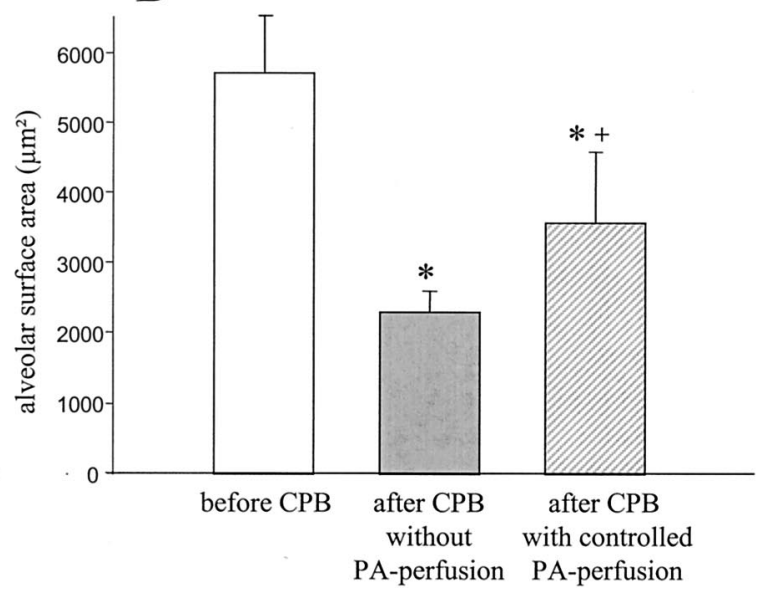

Figure 3. Alveolar septal thickness (A) and alveolar surface area (B) before CPB and at the end of reperfusion after CPB with or without controlled PA perfusion. Bar heights represent mean; error bars represent SD; $\mathbf{n}=\mathbf{9}$ in each group. Asterisk indicates $P<.01$ versus before CPB; plus sign indicates $P<.01$ versus CPB without controlled PA perfusion.

We have demonstrated that perfusion of the lung with normothermic, oxygenated blood during CPB can significantly reduce metabolic and ultrastructural changes of lung tissue. Similar parenchymal alterations have been reported in children with pulmonary hypertension at the end of CPB after surgical repair of congenital heart anomalies. ${ }^{19}$ In infants younger than 6 months, the ultrastructural changes (eg, increase in alveolar septal thickness) were correlated with early death and prolonged mechanical ventilation. ${ }^{19}$ There is already clinical evidence that pulmonary perfusion has beneficial effects on the maintenance of lung function in infants. ${ }^{20,21}$ Continuous perfusion of the lung during $\mathrm{CPB}$ resulted in a higher arterial oxygen tension in infants after CPB than was seen with conventional CPB techniques. ${ }^{20}$ Suzuki and coworkers ${ }^{20}$ speculated that the impaired arterial oxygen tension is related to ischemic injury of the lung during conventional CPB. We provide experimental evidence that this speculation is accurate. An unexpected observation was the prevention of changes caused by CPB in the BAL fluids when the pulmonary arteries were perfused. Accumulation of neutrophils and increases in lactate dehydrogenase and elastase activities in BAL fluids are considered indicators of an inflammatory response of the lungs, ${ }^{22,23}$ which in turn is thought to be caused by the $\mathrm{CPB}$ 
TABLE 3. Solute components and cell counts detected in BAL fluids obtained before CPB and at the end of reperfusion after CPB with or without controlled perfusion of the PA

\begin{tabular}{lrcc}
\hline Parameter & $\begin{array}{c}\text { Control } \\
(\mathbf{n}=\mathbf{6})\end{array}$ & $\begin{array}{c}\text { CPB without } \\
\text { PA perfusion } \\
(\mathbf{n}=\mathbf{9})\end{array}$ & $\begin{array}{c}\text { CPB with PA } \\
\text { perfusion } \\
(\mathbf{n}=\mathbf{9})\end{array}$ \\
\hline $\begin{array}{l}\text { Albumin (mg/L) } \\
\text { Lactate dehydrogenase }\end{array}$ & $7.5 \pm 4.5$ & $24.2 \pm 8.9^{*}$ & $11.1 \pm 6.9$ \\
$\quad$ (IU/L) & & $11.6 \pm 5.7$ & $4.3 \pm 2.8$ \\
Elastase $(\mu \mathrm{g} / \mathrm{L})$ & $4.1 \pm 3.2$ & $9.5 \pm 6.2$ & $5.5 \pm 5.7$ \\
Macrophages (\%) & $97.9 \pm 1.4$ & $92.2 \pm 5.3^{*}$ & $94.3 \pm 2.0$ \\
Neutrophils (\%) & $0.7 \pm 0.5$ & $6.1 \pm 4.8^{*}$ & $3.1 \pm 1.0^{*}$ \\
Lymphocytes (\%) & $1.4 \pm 1.4$ & $1.7 \pm 0.6$ & $2.6 \pm 1.5$ \\
\hline
\end{tabular}

Values are mean \pm SD.

${ }^{*} P<.02$ versus control.

circuit. If this were the case, pulmonary perfusion during CPB should not have been able to affect these parameters. Yet controlled perfusion of the PA prevented the accumulation of neutrophils and the leakage of lactate dehydrogenase and elastase into the BAL fluids. This observation may suggest a different pathologic mechanism for CPB-associated inflammatory changes, at least in lungs.

\section{Clinical Relevance}

A specific problem that may provide an example of the clinical relevance of our conclusions is the treatment of infants with single-ventricle physiology and shunt-dependent pulmonary circulation. These patients may have to be given postoperative mechanical support by extracorporeal membrane oxygenation (ECMO). ${ }^{24-26}$ During ECMO, the mode of perfusion is comparable to the mode during CPB. The difference is the duration of support (days on ECMO vs hours on $\mathrm{CPB}$ ). This patient population has a poor outcome after ECMO support, which among other things is due to severe pulmonary dysfunction. Thus far, complete occlusion of the systemic-pulmonary shunt has been recommended to avoid an overcirculation to the lung and has been performed by most surgeons. ${ }^{25}$ Recently, Jaggers and coworkers $^{24}$ left the shunt open while the patients were receiving ECMO support. In this small series of infants, survival after ECMO support was improved relative to a group of patients in whom the shunts were closed. Our experimental finding that the bronchial arterial blood flow is minimized during CPB may also hold true during ECMO, although there may be still some antegrade flow to the right ventricle. We demonstrated, however, that flow to the PA did not affect the decrease in bronchial flow with the beginning of CPB. Because perfusion of the lung with oxygenated blood during CPB was able to ameliorate the ischemic changes of the lung, the improved outcome of the infants in whom the shunt was left open by Jaggers and coworkers ${ }^{24}$ may possibly be explained by the prevention of ischemia of the lungs. These observations warrant further investigation.

We conclude that CPB causes a reduction in bronchial arterial blood flow, which is associated with an injury of the lung. Controlled pulmonary perfusion reduces injury to the lung during $\mathrm{CPB}$. The inflammatory response, as evidenced by BAL fluid, may be caused by ischemia.

We thank Dr W.G. Williams (Hospital for Sick Children, Toronto, Canada) for helpful discussions and valuable suggestions and Dr K. Sarai for surgical mentoring.

\section{References}

1. Kirklin JK, Westaby S, Blackstone EH, Kirklin JW, Chenoweth DE, Pacifico AD. Complement and the damaging effects of cardiopulmonary bypass. J Thorac Cardiovasc Surg. 1983;86:845-57.

2. Kirklin JK. Prospects for understanding and eliminating the deleterious effects of cardiopulmonary bypass. Ann Thorac Surg. 1991;51: 529-31.

3. Sonntag J, Dähnert I, Stiller B, Hetzer R, Lange PE. Complement and contact activation during cardiovascular operations in infants. Ann Thorac Surg. 1998;65:525-31.

4. Boyle EM, Pohlman TH, Johnson MC, Verrier ED. The systemic inflammatory response. Ann Thorac Surg. 1997;64:S31-7.

5. Chai PJ, Williamson JA, Lodge AJ, Daggett CW, Scarborough JE, Meliones JN, et al. Effects of ischemia on pulmonary dysfunction after cardiopulmonary bypass. Ann Thorac Surg. 1999;67:731-5.

6. Virchow R. Über die Standpunkte in der wissenschaftlichen Medizin. Virchows Arch. 1847;1:1-19.

7. Schlensak C, Doenst T, Preußer S, Wunderlich M, Kleinschmidt M, Beyersdorf $\mathrm{F}$. Bronchial artery perfusion during cardiopulmonary bypass does not prevent ischemia of the lung in piglets: assessment of bronchial artery blood flow with flourescent microspheres. Eur J Cardiothorac Surg. 2001;19:326-32.

8. Sakka SG, Wallbridge DR, Heusch G. Methods for the measurement of coronary blood flow and myocardial perfusion. Basic Res Cardiol 1996;91:155-178.

9. Riedler J, Grigg J, Robertson CF. Role of bronchoalveolar lavage in children with lung disease. Eur Respir J. 1995;8:1725-30.

10. Jindal SK, Lakshimnarayan S, Kirk W, Butler J. Acute increase in anastomotic bronchial blood flow after pulmonary artery obstruction. J Appl Physiol. 1984;53:272-9.

11. Baile EM, Ling H, Heyworth JR, Hogg JC, Pare PD. Bronchopulmonary anastomotic and noncoronary collateral blood flow in humans during cardiopulmonary bypass. Chest. 1985;87:749-54.

12. Baile EM, Nelems JM, Schulzer M, Pare PD. Measurement of regional arterial blood flow and bronchial vascular resistance in dogs. J Appl Physiol. 1982;53:1044-9.

13. Brunner HD, Schmidt CF. Blood flow in the bronchial artery of the anesthetized dog. Am J Physiol. 1946;148:646-66.

14. Deal CW, Louis E, Kerth WJ, Osborn JJ, Gerbode F. Bronchopulmonary precapillary blood flow during cardiopulmonary bypass. Am Heart J. 1968;75:43-38

15. Fritts HW, Harris P, Chidsey CA, Clauss RH, Cournand A. Estimation of flow through bronchial-pulmonary vascular anastomoses with the use of T-1824 dye. Circulation. 1961;23:390-8.

16. Malik AB, Tracy SE. Bronchovascular adjustment after pulmonary embolism. Chest. 1980;83:151-3.

17. Ündar A, Masai T, Yang SQ, Goddard-Finegold J, Frazier OH, Fraser C. Effects of perfusion mode on regional and global organ blood flow in a neonatal piglet model. Ann Thorac Surg. 1999;68:1336-42.

18. Lodge A, Undar A, Daggett C, Runge T, Calhoon J, Ungerleider R. Regional blood flow during pulsatile cardiopulmonary bypass and after circulatory arrest in an infant model. Ann Thorac Surg. 1997;63:1243-50.

19. Ogawa K, Ito H, Toriyama A, Yamamoto T, Yamaguchi M, Horikoshi $\mathrm{K}$, et al. Lung pathology in infants with severe pulmonary hypertension and cardiac disease. J Thorac Cardiovasc Surg. 1979; 77:728-32. 
20. Suzuki T, Fukuda T, Ito T, Inoue Y, Cho Y, Kashima I. Continuous pulmonary perfusion during cardiopulmonary bypass prevents lung injury in infants. Ann Thorac Surg 2000;69:602-6.

21. Richter JA, Meisner H, Tassani P, Barankay A, Dietrich W, Braun SL. Drew-Anderson technique attenuates systemic inflammatory response syndrome and improves respiratory function after coronary artery bypass grafting. Ann Thorac Surg. 1999;69:77-83.

22. Sinclair DG, Haslam PL, Quinlan GJ, Pepper JR, Evans TW. The effect of cardiopulmonary bypass on intestinal and pulmonary endothelial permeability. Chest. 1995;108:718-24.

23. Drent M, Cobben NA, Henderson RF, Wouters EF, van DieijenVisser M. Usefulness of lactate dehydrogenase and its isoenzymes as indicators of lung damage or inflammation. Eur Respir J. 1996; 9:1736-42.

24. Jaggers JJ, Forbess JM, Shah AS, Meliones JN, Kirshbom PM, Miller $\mathrm{CE}$, et al. Extracorporeal membrane oxygenation for infant postcardiotomy support: significance of shunt management. Ann Thorac Surg. 2000;69:1476-83.

25. Kulik T, Moler F, Palmisano J, Custer J, Mosca R, Bove E, et al Outcome-associated factors in pediatric patients treated with extracorporeal membrane oxygenator after cardiac surgery. Circulation 1996;94 (9 Suppl):II63-8.

26. del Nido P. Extracorporeal membrane oxygenation for cardiac support in children. Ann Thorac Surg. 1996;61:336-9.

The Journal of Thoracic and Cardiovascular Surgery delivers the information you need now. Articles usually appear within four months of acceptance. 